\title{
Prevalence of Burnout in Board Certified Family Physicians
}

\author{
James C. Puffer, MD, H. Clifton Knight, MD, Thomas R. O'Neill, PhD, \\ Monee Rassolian, MD, Andrew W. Bazemore, MD, Lars E. Peterson, MD, PhD, and \\ Elizabeth G. Baxley, $M D$
}

Physician burnout has become a critical issue in a rapidly changing health care environment and is reported to be increasing. However, little is known about the prevalence of this problem among boardcertified family physicians. Using an abbreviated burnout survey, we found a lower prevalence of this problem than has been previously reported. (J Am Board Fam Med 2017;30:125-126.)

Keywords: Burnout, Professional; Physicians, Family; Prevalence; Surveys and Questionnaires

Burnout, the physical and mental exhaustion resulting from working in a stressful environment, has been reported in $>50 \%$ of all physicians and $63 \%$ of family physicians, and it seems to be increasing. ${ }^{1}$ Even when working in highly satisfying environments, as many as $40 \%$ of physicians may report symptoms of burnout. ${ }^{2}$ Given this information, we were interested in determining the prevalence of this problem among board-certified family physicians.

We administered the Mini $Z$ burnout survey, an abbreviated survey instrument developed from the Physician Worklife Survey and the Minimizing Error; Maximizing Outcomes (MEMO) clinician sur-

This article was externally peer reviewed.

Submitted 16 September 2016; revised 11 November 2016; accepted 16 November 2016.

From the American Board of Family Medicine, Lexington, KY (JCP, TRO, LEP); the American Academy of Family Physicians, Leawood, KS (HCK); the McLaren Flint Family Medicine Residency, Michigan State University, Flint (MR); the Robert Graham Center, Washington, DC (AWB); and Department of Family Medicine, East Carolina University, Greeneville, NC (EGB).

Funding: none.

Conflict of interest: JCP, TRO, and LEP are employees of the ABFM.

Corresponding author: James C. Puffer, MD, American Board of Family Medicine, 1648 McGrathiana Pkwy, 5th Floor, Lexington, KY 40511 (E-mail: jpuffer@theabfm.org).

\footnotetext{
See Related Commentary on Page 127.
}

$\mathrm{vey}^{3-5}$ to a subset of practicing family physicians applying to take the American Board of Family Medicine (ABFM) 2016 Family Medicine Certification Examination to continue their certification. Burnout was defined as a positive response to any 3 of 5 potential options offered for the following question in the survey: "Using your own definition of 'burnout,' please select 1 of the answers below." This single item has been shown to be a valid measure of burnout when compared with the Maslach Burnout Inventory. ${ }^{6,7}$ Using data from the ABFM administrative database and responses to the other Mini $Z$ questions, we performed bivariate analyses to determine factors that were significantly associated with burnout as self-reported on the Mini $Z$ instrument.

A total of 2099 family physicians were administered the Mini $Z$, with a response rate of $100 \%$. Burnout was reported by 515 physicians (24.5\%); female sex and age were significantly associated with burnout (Figure 1).

Our data suggest that the prevalence of burnout among board-certified family physicians may be lower than previously reported for family physicians in general, ${ }^{1}$ with younger family physicians and women being at particular risk. Although this sample represents only a small number of all 89,223 board-certified ABFM diplomates, it is highly representative of those ABFM diplomates who are $>5$ years out of residency. The data were randomly sampled from diplomates taking the examination in 
Figure 1. Prevalence of burnout among board-certified family physicians by sex and age.

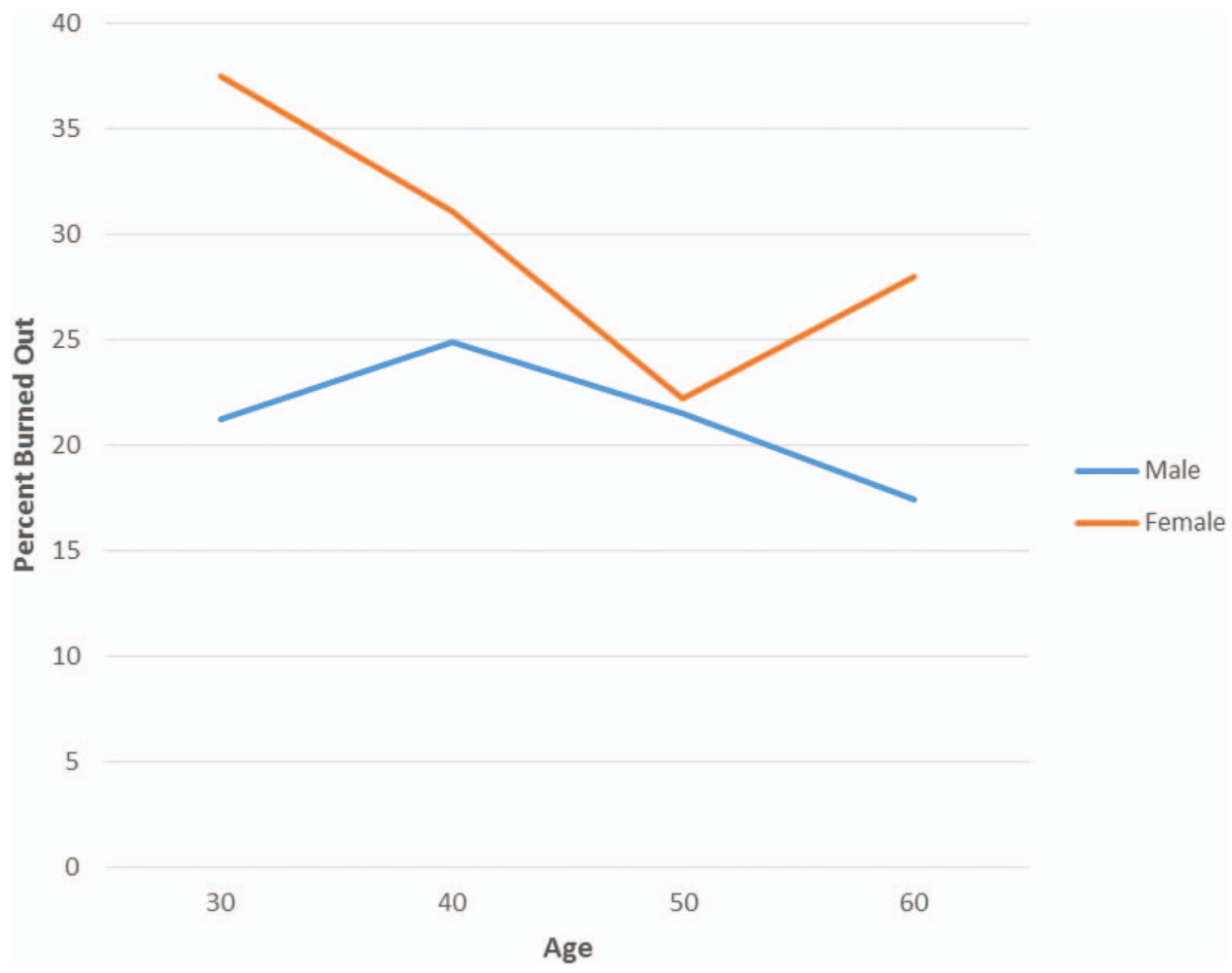

2016 to continue their certification, and $100 \%$ of those surveyed responded.

Additional data collection with subsequent administrations of the ABFM Family Medicine Certification Examination will allow these initial findings to be validated and changes over time to be monitored. However, the lower prevalence of burnout identified among this cohort of boardcertified family physicians and the higher reported rates among younger and female family physicians are intriguing findings that deserve further investigation. Better understanding of and addressing the correlated characteristics found in these and subsequent data may help improve professional satisfaction and increase the well-being of family physicians.

To see this article online, please go to: http://jabfm.org/content/ 30/2/125.full.

\section{References}

1. Shanafelt TD, Hasan O, Dyrbye LN, et al. Changes in burnout and satisfaction with work-life balance in physicians and the general U.S. working population between 2011 and 2014. Mayo Clin Proc 2015;90: 1600-13.

2. Shanafelt TD, Gorringe G, Menaker R, et al. Impact of organizational leadership on physician burnout and satisfaction. Mayo Clin Proc 2015;90:432-40.

3. American Medical Association. Steps forward. Preventing physician burnout. 2015. Available from: https:// www.stepsforward.org/modules/physician-burnout. Accessed August 10, 2016.

4. Williams ES, Konrad TR, Linzer M, et al. Refining the measurement of physician job satisfaction: results from the Physician Worklife Survey. SGIM Career Satisfaction Study Group. Society of General Internal Medicine. Med Care 1999;37:1140-54.

5. Linzer M, Manwell LB, Williams ES, et al. Working conditions in primary care: physician reactions and care quality. Ann Intern Med 2009;151:28-36.

6. Rohland B, Kruse G, Rohrer J. Validation of a single-item measure of burnout against the Maslach Burnout Inventory among physicians. Stress Health 2004;20:75-9.

7. Dolan ED, Mohr D, Lempa M, et al. Using a single item to measure burnout in primary care staff: a psychometric evaluation. J Gen Intern Med 2015;30: $582-7$. 